\title{
Guía de práctica clínica: Guía de Dengue para el equipo de salud
}

\section{Role of glucosamine in the treatment of osteoarthritis}

Dirección de Epidemiología-Ministerio de Salud de la Nación de Argentina. Guía para el equipo de salud Nro. 2. Enfermedades infecciosas: dengue. Febrero 2009.

\section{Introducción}

El dengue es una enfermedad causada por un virus, transmitida a través de un mosquito, el Aedes aegypti, de hábitos domiciliarios, por lo que la enfermedad es predominantemente urbana. El mosquito se desarrolla en envases caseros que puedan retener agua estancada, como por ejemplo floreros ${ }^{1-4}$. Toda persona que es picada por un mosquito infectado puede desarrollar la enfermedad. El virus del dengue tiene cuatro serotipos y la infección con un serotipo confiere inmunidad permanente contra el mismo y sólo por unos meses contra los otros serotipos. De esta manera, una persona podría tener dengue hasta cuatro veces, una por cada serotipo.

El dengue es un problema creciente de Salud Pública en el mundo, debido a un aumento de la población de Aedes aegypti (por la urbanización rápida y desorganizada con insuficiente provisión de agua potable y recolección de residuos, por la gran producción de recipientes descartables que sirven como criaderos de mosquitos, y por la resistencia del Aedes aegypti a los insecticidas) y a la falta de una vacuna eficaz para prevenir la enfermedad.

\section{Distribución}

En Argentina, durante la última década, se han registrado casos autóctonos ${ }^{\S}$ de dengue en las provincias de Salta, Jujuy,
Formosa, Misiones y Corrientes.

El comportamiento del dengue es epidémico, restringido a los meses de mayor temperatura (noviembre a mayo) y en estrecha relación con la ocurrencia de brotes en los países limítrofes.

\section{Forma de transmisión}

El dengue se transmite a través de la picadura de la hembra del mosquito Aedes aegypti, que debe estar previamente infectado con el virus para transmitir la enfermedad. Los enfermos pueden infectar a los mosquitos desde días antes de la aparición de los síntomas hasta cinco a seis días después del comienzo de los mismos. Luego de un período de incubación de ocho a 12 días, el mosquito será capaz de infectar a un individuo susceptible, y permanecerá infectante el resto de su vida. La enfermedad no se transmite de persona a persona, ni a través de objetos.

\section{Manifestaciones y formas clínicas}

Luego de un período de incubación de tres a 14 días, pueden aparecer las manifestaciones clínicas. Sin embargo, una alta proporción de las personas que se infectan con dengue serán asintomáticas, tal y como se expone en la Figura 1.

Figura 1. Formas clínicas de Dengue.

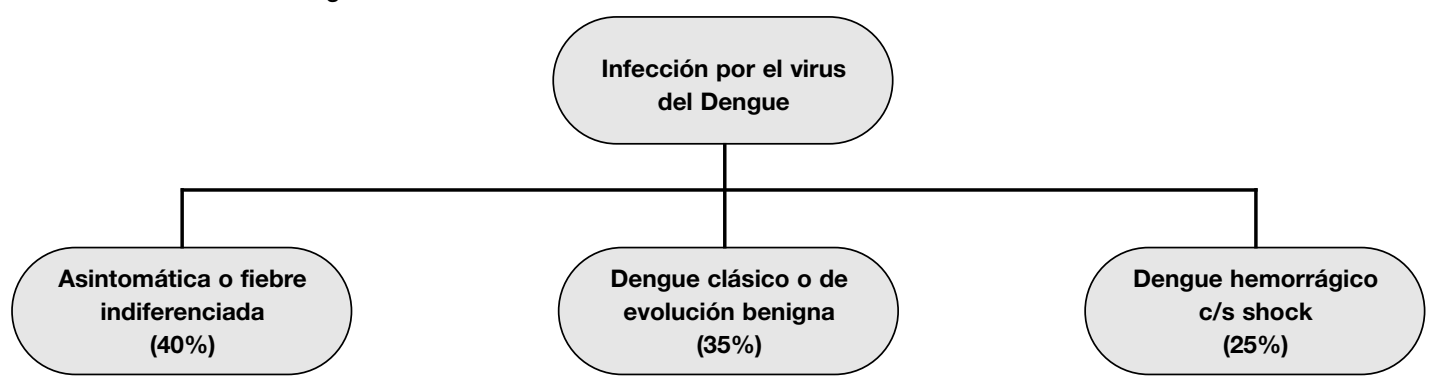

\section{¿Cuándo sospechar dengue?}

Dengue clásico: caso sospechoso

Síndrome febril (menos de siete días, sin afección de vías aéreas superiores ni etiología definida)

Dos de los siguientes síntomas: cefalea, dolor retroorbitario, mialgias/artralgias, erupción cutánea, manifestaciones hemorrágicas leves

Que viva o haya viajado a zona endémica de dengue o con presencia del vector.
Dengue Hemorrágico5: caso sospechoso

Fiebre o antecedente reciente de fiebre

Manifestaciones hemorrágicas

$+$

Trombocitopenia

$+$

Aumento de la permeabilidad capilar manifestada por disminución de $\mathbf{2 0} \%$ o más del hematocrito luego de la hidratación o hematocrito igual o superior a $\mathbf{2 0} \%$ por encima del promedio para la edad y población o signos asociados a extravasación de plasma (derrame pleural, ascitis o hipoproteinemia). 


\section{¿Cómo se confirma el Dengue?}

Si la muestra es tomada antes de los cinco días de iniciados los síntomas se solicitará aislamiento del virus y/o detección del genoma viral de muestras de suero y/o tejidos. Si la muestra es tomada luego de los cinco días de iniciados los síntomas, el diagnóstico se confirmará a través de la documentación de un aumento de por lo menos cuatro veces en los títulos de anticuerpos IGG del virus del dengue (seroconversión) en muestras de suero obtenidas durante la fase aguda y de convalecencia (tomadas con un intervalo de diez a 15 días) y habiendo descartado reacciones cruzadas con otros virus pertenecientes a la familia Flaviviridae. Sin embargo, dentro de un contexto epidemiológico que lo justifique, una única muestra positiva para lgM puede confirmar un caso.
Ante una epidemia y ante episodios de transmisión comprobada de dengue, luego de la confirmación serológica del diagnóstico de dengue en los primeros casos, los siguientes casos se confirman por criterios clínico-epidemiológicos.

Si bien es necesario continuar realizando análisis serológicos y moleculares para verificar si existe introducción de otro serotipo, los estudios de laboratorio en una epidemia se centralizan hacia los casos graves, atípicos o hemorrágicos y para monitorear la expansión del brote hacia nuevas áreas.

\section{¿Cómo se trata el paciente con Dengue?}

\section{Evaluar signos de alarma}

Dolor abdominal intenso o sostenido. Vómitos abundantes y frecuentes. Descenso brusco de temperatura, hasta la hipotermia. Irritabilidad, somnolencia

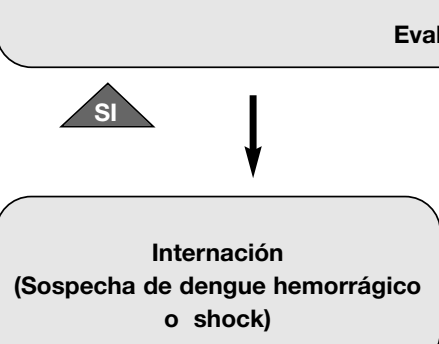

Evaluar dificultad de seguimiento

$$
\text { o shock) }
$$

\section{- Dar pautas de alarma}

Tratamiento Ambulatorio sintomático

- Reposo y reposición de líquidos

- Solicitar Hemograma, recuento de plaquetas, sedimento urinario

Control ambulatorio en 24-48h (Proceder como al inicio evaluando signos de alarma)

- Control de contactos

- Proteger al paciente de picaduras de mosquitos mientras esté febril

- No dar aspirina

¿Qué hacer si se confirma el caso sospechoso de dengue ${ }^{6-11}$ ?

\section{Si Ud. se encuentra en una zona de riesgo de dengue}

Informar al paciente, a la familia y a la comunidad sobre la enfermedad, el mosquito, el modo de transmisión y los métodos de prevención.

Explicar a la familia y al paciente la necesidad de proteger al paciente de las picaduras de mosquitos, utilizando barreras como telas mosquiteras mientras el paciente se encuentre febril.

Vigilar la aparición de casos febriles en las nueve manzanas alrededor del caso índice, y donde se hubiere detectado un caso sospechoso.

Intensificar la tarea de eliminar potenciales sitios de reproducción del mosquito, mediante la destrucción o inversión de recipientes con agua o mediante la aplicación de larvicidas.

\section{Si Ud. NO se encuentra en una zona de riesgo de dengue}

Investigar los sitios a los que concurrió el paciente entre los cinco y los diez días previos a la aparición de la enfermedad, manteniendo en especial vigilancia a todas aquellas personas que hayan visitado el mismo lugar.

Explicar a la familia y al paciente la necesidad de proteger al mismo de las picaduras de mosquitos

mientras el paciente se encuentre febril, para evitar la infección de otros mosquitos que podrían transmitir la enfermedad.

Realizar medidas de difusión y educación en la comunidad informando al paciente, a la familia

y a la comunidad en general sobre la enfermedad, el mosquito, el modo de transmisión y los métodos de prevención.

Intensificar la tarea de eliminar potenciales sitios de reproducción del mosquito. 
Mientras no se cuente con una vacuna, las estrategias de control deben estar dirigidas $\mathrm{a}^{2-4}$ :

- Reducir la población de mosquitos.

- Protegerse de las picaduras de los mismos mediante el uso de ropa adecuada blanca y de manga larga, el uso de repelentes, de telas mosquiteros, de espirales y/o tabletas repelentes.

- Detectar y tratar precoz y adecuadamente a los casos de la enfermedad.

Hay acciones simples y económicas que pueden ayudar al control del mosquito sin utilizar productos químicos. Estas son las tendientes a la eliminación de potenciales criaderos del mosquito mediante la eliminación o el vaciado de tachos, latas, botellas plásticas, cubiertas en desuso, neumáticos viejos y otros recipientes que pueden contener agua.

La apropiación y el empoderamiento de la comunidad en los programas de control del dengue, son requisitos fundamentales para su éxito y sustentabilidad.

\section{¿Cómo notificar el caso de dengue?}

Se destacan tres síndromes que requieren notificación:

- Síndrome febril: paciente de cualquier edad y sexo que presente fiebre durante menos de siete días, sin afección de las vías aéreas superiores y sin etiología definida.
La notificación deberá ser individual e inmediata y a través de la planilla de notificación de síndrome febril.

- Dengue Clásico: si se trata del primer caso o de los primeros casos que se registran en el área o en la temporada, en un área donde ya ha habido casos de dengue (episodio interbrote) la notificación deberá ser individual e inmediata y mediante la planilla de notificación de síndrome febril. Si se trata de los casos subsiguientes a otros casos ya confirmados en el área o la temporada (un episodio intrabrote) la notificación será de número de casos, y debe ser enviada semanalmente a través de su carga en el Sistema Nacional de Vigilancia de la Salud (SNVS) o de la planilla C2 impresa.

- Dengue Hemorrágico o shock por Dengue: siempre la notificación debe ser individual e inmediata, mediante la ficha de notificación correspondiente. Se debe utilizar la vía más rápida disponible: teléfono, fax, correo, etc., al nivel superior que corresponda, sea el Hospital o el Área Programática.

Las planillas de notificación, así como la versión completa de esta guía se encuentran disponibles en:

http://www.msal.gov.ar/htm/site/pdf/guia_dengue.pdf.

Para más información comuníquese al 0-800-222-1002.

Wurcel V. Guía de Dengue para el Equipo de Salud. Evid. actual. práct. ambul; 12(1): $36-38$ Ene-Mar. 2009. Resumido de: Dirección de Epidemiología Ministerio de Salud de la Nación. Guía para el equipo de salud Nro. 2. Enfermedades infecciosas: dengue. Febrero 2009.

\section{Bibliografía}

1. Guía de Atención del Dengue, Servicio de Salud Colombia

2. Bisset $\mathrm{J}$ y col.Resistencia a insecticidas y mecanismos de resistencia en Aedes aegypti de 2 provincias del Perú.

3. Mandell G y col. Principles and Practice of Infectious Diseases. 6th ed. 2005.

4. Ministerio de Salud y Acción Social, Manual de Normas y Procedimientos de Vigilancia y Control de Enfermedades de Notificación Obligatoria, Argentina 2007

5. Organización Mundial de la Salud, Dengue haemorrhagic fever: diagnosis, treatment, prevention and control. 2nd edition. 1997

6. Organización Panamericana de la Salud 1997. Plan Continental de Ampliación e Intensificación del Combate al Aedes aegypti; Informe de un Grupo de Trabajo: OPS

7. Organización Panamericana de la Salud. 1998. Taller Subregional de Evaluación del Plan Continental de Ampliación e Intensificación del Combate al Aedes aegypti. Paises Andinos, Aruba y Cuba. Retorno del Dengue a las Américas, llamada de alerta a los sistemas de vigilancia.

8. Organización Panamericana de la Salud Programa de enfermedades transmisibles Plan Detallado de Acción para la próxima generación: Prevención y Control del Dengue, Junio de

8. Organizz.
1999.

9. Organizacion Panamericana de la Salud. Dengue y Dengue hemorrágico en las Américas: Guías para la prevención y control. Publicación científica de la OPS No 548,1995

10. Organización Panamericana de la Salud, El Control de las enfermedades transmisibles, 18 edición, 2005.

11. Organización Mundial de la Salud, Dengue/DHF Management of Dengue Epidemic Annex 8 Clinical Case Definition for Dengue Haemorrhagic Fever Management of Dengue Epidemic,

en línea en www.searo.who.int/en/Section10/ Section332/Section366_1153.htm 


\section{Información sobre el dengue para los pacientes}

\section{¿Qué es el dengue y cómo se contagia?}

El dengue es una enfermedad viral transmitida por mosquitos que se caracteriza por producir un importante dolor en las articulaciones y los músculos, inflamación de los ganglios y erupción en la piel. Muchos conocen al dengue como enfermedad "rompehuesos" por el intenso dolor que produce en los músculos y las articulaciones.

No todos los mosquitos contagian el dengue, sólo aquellos que previamente han picado a un individuo enfermo. Existen cuatro tipos del virus del dengue y una persona puede tener hasta cuatro enfermedades por dengue durante su vida. El mosquito que transmite el dengue, se desarrolla en envases caseros que puedan retener agua, tales como latas, barriles o tanques, llantas descartadas, floreros, y cualquier otro recipiente que contenga agua estancada.

\section{¿Qué puedo hacer para prevenir el dengue?}

No hay vacuna disponible contra el dengue, por lo que si vivimos o vamos a viajar a una zona de riesgo la mejor prevención es evitar ser picados por mosquitos. Para eso:

- Aplique repelente contra insectos en la piel expuesta.

- Rocíe su ropa con repelentes ya que los mosquitos pueden picar a través de la ropa de tela fina.

- Use camisas de manga larga y pantalones largos.

- Use mosquiteros en las camas si su habitación no tiene acondicionador de aire. Para protección adicional, rocíe el mosquitero con insecticida.

- Rocíe insecticidas en su habitación antes de la hora de acostarse.

\section{¿Cuáles son las zonas de riesgo para enfermar de dengue?}

En Argentina el dengue se produce en los meses de calor, generalmente de noviembre a mayo, siendo las provincias de Salta, Jujuy, Formosa, Misiones y Corrientes las de mayor riesgo.

\section{¿Cómo puedo saber si tengo dengue?}

En la mayoría de los casos el dengue puede producir síntomas parecidos a una gripe pero, en algunos casos puede producir una enfermedad grave con hemorragias.

Si ha viajado o vive en una zona donde se conocen casos de dengue y tiene fiebre alta, con intenso malestar general, dolor de cabeza y/o detrás de los ojos, y dolores de los músculos y articulaciones, consulte al Centro de Salud, y allí le dirán si es posible que se trate de dengue y qué debe hacer.

\section{¿Hay algún tratamiento para el dengue?}

No hay un tratamiento específico para la enfermedad, solo se realiza tratamiento de los síntomas. Por eso, ante la sospecha es importante concurrir al Centro de Salud, donde le indicarán las medidas adecuadas a cada caso.

Evite tomar aspirina, porque puede favorecer las hemorragias. Tome Paracetamol en caso de dolor intenso o fiebre.

Es muy importante utilizar mosquiteros donde se encuentra el paciente mientras tenga fiebre, para evitar que sea picado por mosquitos, y que de esa manera otros mosquitos se infecten y puedan contagiar a otra persona.

Siga las recomendaciones que le ha indicado el equipo de salud, para eliminar los mosquitos de su casa.

\section{¿Qué puedo hacer?}

Si controlamos la proliferación de los mosquitos, evitaremos la transmisión de la infección así que:

- Revise su casa, y las zonas de los alrededores como jardines y quintas, en búsqueda de recipientes que puedan acumular agua estancada, y que no tengan utilidad.

- Elimine el agua de los huecos de árboles, rocas, paredes, pozos, letrinas abandonadas, por ejemplo rellene huecos de tapias y paredes donde pueda juntarse agua de lluvia.

- Entierre todo tipo de basura como latas, cáscaras, llantas y demás recipientes $u$ objetos que puedan almacenar agua.

- Ordene los recipientes que puedan acumular agua, colóquelos boca abajo o colóqueles una tapa.

- Mantenga tapados los tanques y recipientes que colectan agua o puedan recolectarla si llueve.

- Cambie el agua de los floreros cada tres días y frote las paredes de los mismos. De ser posible, utilice productos alternativos en lugar de agua (geles, arena).

- Cambie el agua cada tres días y lave con esponja los bebederos de animales.

- Mantenga limpias, cloradas o vacías las piletas de natación fuera de la temporada.

- Mantenga los patios desmalezados y destapados los desagües de lluvia de los techos.

- Hable con sus amigos y vecinos para informarlos acerca de las medidas para prevenir el dengue. 